\title{
The effect of educational program based on the theory of planned behavior on HIV prevention skills
}

\author{
Elnaz Ashrafi ${ }^{1}$, Parisa Kasmaei ${ }^{2}$, Fardin Mehrabian², Saeed Omidi², Iraj Zareban³ ${ }^{3}$ Mahmood Karimy ${ }^{4}$, \\ Katayun Haryalchi ${ }^{1}$, Hossein Izadi Rad ${ }^{3}$, Nooshin Rouhani Tonekaboni ${ }^{2}$ \\ ${ }^{1}$ School of Health, Guilan University of Medical Sciences, Rasht, Iran \\ ${ }^{2}$ Department of Health Education and Promotion, Research Center of Health and Environment, School of Health, Guilan University \\ of Medical Sciences, Rasht, Iran \\ ${ }^{3}$ Health Promotion Research Center, Zahedan University of Medical Science, Zahedan, Iran \\ ${ }^{4}$ Social Determinants of Health Research Center, Saveh University of Medical Sciences, Saveh, Iran
}

\begin{abstract}
Introduction: The prevalence of acquired immune deficiency syndrome (AIDS) is dramatically expanding in the world and the only way to deal with it is through health education. This study sought to determine the effect of educational intervention based on the theory of planned behavior (TPB) on AIDS preventive behaviors in nursing and midwifery students.

Material and methods: This was a quasi-experimental study conducted in 2016, and included 104 nursing and midwifery students from Guilan University of Medical Sciences. A questionnaire consisted of sections with demographic characteristics, awareness, behaviors, and constructs of the theory of planned behavior, and was provided to every participant. The questionnaire content validity rate was 0.8 , content validity index was equal to 0.82 , and Cronbach's a coefficient test was 0.9. After collecting data in both groups, educational intervention was conducted within the framework of the theory of planned behavior in the intervention group. Data was collected before the intervention and three months later and was analyzed with SPSS statistics version 21 .

Results: There was no significant difference between the two groups in terms of demographic variables $(p>0.05)$. Additionally, no significant differences were noted between the intervention and control groups before the educational intervention in terms of awareness, attitude, subjective norms, perceived behavioral control, behavioral intention, and preventive behaviors $(p>0.05)$. However, after the implementation of educational program, these variables significantly increased in the intervention group $(p<0.05)$.

Conclusions: The TPB was effective in teaching students in the field of AIDS prevention skills. Therefore, it is recommended to use the theory of planned behavior for human immunodeficiency virus prevention behaviors.
\end{abstract}

HIV AIDS Rev 2020; 19, 3: 180-186 DOI: https://doi.org/10.5114/hivar.2020.99689

Key words: AIDS, education, students.

Address for correspondence: Parisa Kasmaei, Department of Health Education and Promotion, Research Center of Health and Environment, School of Health, Guilan University of Medical Sciences, Realat St., Rasht, I.R. Iran, postcode: 41857-33411, phone: (+98) (13) 33849411, e-mail: kasmayparisa@yahoo.com; parisa_kasmaei@gums.ac.ir 


\section{Introduction}

Human immunodeficiency virus (HIV) is a major public health concern that can influence every part of human life [1]. HIV is the largest lethal infectious disease and the fourth leading cause of death across the globe [2]. Given the economic and social disadvantages associated with its spread, it can be acknowledged that the most important challenge of the present time is the prevention from development of the disease $[3,4]$. According to the World Health Organization (WHO) report, the prevalence rate of HIV/acquired immunodeficiency syndrome (AIDS) in Iran has risen from low to high [5]. So far, no definitive vaccine has been discovered for AIDS, and the only way to control the spread of the disease is health education to change dangerous behaviors [6]. Health staff, especially nurses and midwives as well as students of these two disciplines, are the most exposed to this deadly disease. On the other hand, they are in a good position to prevent and educate the community about AIDS, to improve attitudes, beliefs, and ultimately, health behaviors [7-9]. Since educational interventions need to understand attitudes and beliefs of population, and due to the complexity of true nature of relationship between them and health behaviors, health education and health education theories are employed [10]. Therefore, behavior analysis is more efficient with the use of behavior change theories [7]. These theories play a key role in the design and implementation of health education programs [11]. The theory of planned behavior (TPB) is one of the theories of behavior change, which says that the intention is the main determinant of behavior, and the intention of an individual is the perception of which a person has a particular behavior. In other words, the person's intention is a mental and social position that interacts with one's actions. The intention is influenced by three independent constructs, such as attitude, subjective norms, and perceived behavioral control. Attitude reflects the positive or negative evaluation of an individual's behavior, while subjective norms indicate the fact that perceived social pressure may cause a person to behave or not. Perceived behavioral control is the perceived difficulty or easiness of performing a particular behavior, and it is presumed to directly and indirectly affect the behavior. Sometimes, individuals evaluate a behavior positively and intend to do so, when they believe that important influencers think that this behavior should be implemented and its stays under their control $[12,13]$.

Understanding and improvement of the attitudes of nursing students towards HIV are particularly important in health promotion among HIV patients [14]. Therefore, it is essential to investigate attitudes, beliefs, and perceptions of patients' groups they will be working with. Given the lack of awareness, attitude, and AIDS preventive behaviors in nursing and midwifery students $[15,16]$, the role and position of nursing staff and midwifery students in creating healthy behaviors in patients and providing prevention strategies $[8,14]$ of AIDS in society are especially crucial.
In addition, due to the complexity of the true nature of the relationship between attitudes, beliefs, and health behaviors and the need for educational interventions to understand this relationship, as mentioned above, the use of health education and health promotion patterns are required to be utilized [10].

The TPB emphases on peoples' attitude and beliefs, and it is an effective model of behavior change in health education programs [7]. According to Ajzen [17], a person's action is determined by behavioral intentions, which in turn are influenced by an attitude towards the behavior and subjective norms $(\mathrm{SN})$. In addition to attitude towards behavior and subjective norm in the theory of planned behavior, perceived behavioral control can influence intention as well. Moreover, perceived behavioral control influences the individual's decision through behavioral intention. In the TPB, behavioral intention is the most influential predictor of behavior. Behavioral intentions are the factor that describe how hard people are willing to try to perform a behavior [17].

This study was conducted for the first time to determine the effect of educational intervention based on the TPB in the field of AIDS preventive behaviors in nursing and midwifery students of Guilan University of Medical Sciences.

\section{Material and methods}

\section{Study design}

This study was a quasi-experimental study conducted in 2016. The inclusion criteria involved studying in the first grade of nursing and midwifery faculties of Rasht and Langrood of Guilan University of Medical Sciences and a signed written informed consent. The exclusion criteria included incomplete questionnaire and not attending an educational session. According to the

$$
\frac{\left(z_{\mathrm{i}-\alpha / 2}+z_{1-\beta}\right)^{2}\left(\delta_{1}^{2}+\delta_{2}^{2}\right)}{\left(\mu_{1}-\mu_{2}\right)^{2}}
$$

formula refering to the study of Pakpour et al. with a probability of falling $20 \%$, a sample of nursing and midwifery students were selected from two nursing and midwifery faculties in Rasht and Langrood in the North of Iran. From 198 participants, 186 students (93.93\%) were eligible for the study. Of these 186 eligible students, 146 students completed the written informed consent (participation rate, $78.49 \%$ ). In the next stage, 104 students were recruited, and the educational program was implemented in the intervention group. There were 3 and 2 classes at the faculties of nursing and midwifery in Rasht and Langrood, respectively. Therefore, 2 classes of Rasht were selected randomly. In the Langrood, census method was applied. The participants were randomly selected and classified by a random generator number into a control and an intervention group. 


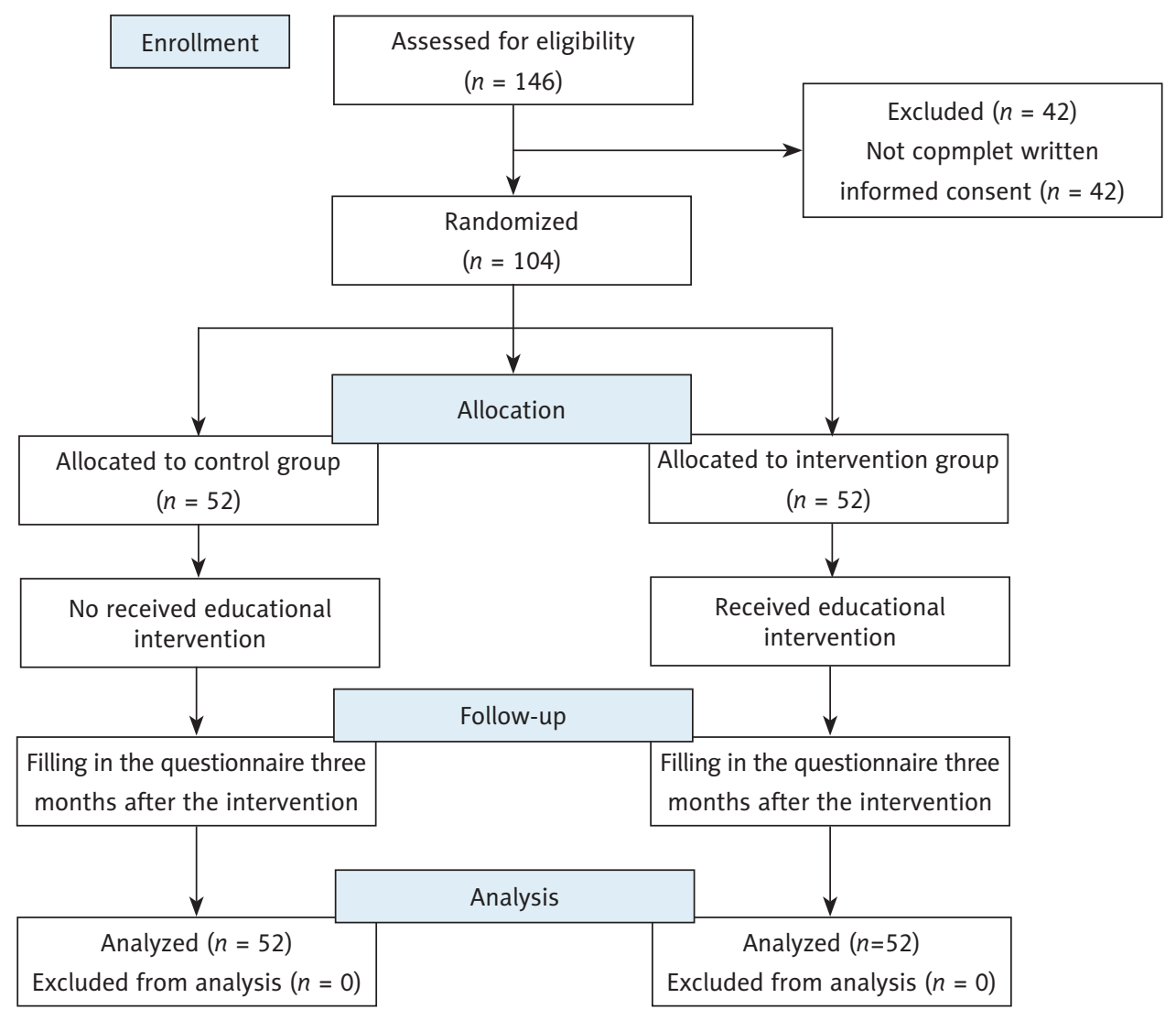

Figure 1. Flow diagram showing the record selection process

This study was approved by the Committee of Ethics affiliated to Guilan University of Medical Sciences, with a necessary coordination of chancellors and university authorities (ethical code No: 94040210).

\section{Instrument}

The data collection tool was a four-part questionnaire called "AIDS Prevention Planned Behavior Scale". The first part of the questionnaire was about measuring demographic characteristics including parental age, parents' occupation, and parents' literacy level. The second part of the questionnaire consisted of 11 items for students' awareness of AIDS prevention that was designed in a multi-choice format, while the third part was measuring the theory of planned behavior based on the five-level Likert scale from 1 to 5 (completely agree, agree, have no idea, disagree, and completely disagree). The fourth part correlated with the AIDS preventive behaviors based on the five-point Likert scale from 1 to 5 (completely agree, agree, have no opinion, disagree, and completely disagree). The number of items related to the construct included 12 items associated with attitude, with a minimum score of 12 and a maximum score of 60 (e.g., "People with AIDS should inform the nurse about their disease"). Ten items were designed to determine perceived behavioral con- trol (e.g., "I am confident I can avoid high-risk behaviors"), ten items were meant to evaluate behavior intention to HIV preventive behaviors (e.g., "Within next two months, I'm going to get tested for HIV"), and ten items were designed to measure subjective norms toward HIV preventive behaviors (e.g., "Most of my friends want me to avoid high-risk behaviors, which lead to AIDS"). Another ten items were intended to define preventive behaviors (e.g., "I should stay away from contaminated things, such as infected needles"), with a minimum achievable score of 10 and a maximum achievable score of 50 for their constructs and skills. In this study, content validity was used to measure the validity of the questionnaire. The questionnaire was delivered to ten experts and faculty members of medical universities (eight health specialists and two infections specialists). The content validity rate (CVR) was set at 0.8 and the content validity index (CVI) equaled to 0.82 . In order to assess the reliability of awareness, internal consistency was used with 0.9 . For assessing the reliability of constructs and skills, Cronbach's $\alpha$ test was applied. For this purpose, a questionnaire was provided to 20 nursing and midwifery students, and Cronbach's $\alpha$ coefficient for the attitude construct was 0.71 and for the subjective norms equaled 0.75. Perceived behavioral control was 0.76 , the behavioral intention construct was equal to 85.8 , and the AIDS prevention skill was 0.75 . 


\section{Intervention}

After collecting information in both groups, an educational intervention was conducted within the framework of the theory of planned behavior in the intervention group. The educational program included four sessions of 40 to 60 minutes for four sub-groups of 13.

\section{Statistical analysis}

Data were collected before the intervention and three months later. The results were entered into SPSS software version 21, and analyzed by Mann-Whitney U test, independent $t$-test, paired $t$-test, Wilcoxon test, and $\chi^{2}$ test. The significance level was considered to be 0.05 .

\section{Results}

The results in Table 1 show that no significant differences were found in background variables, such as the age of parents, parental education, parental occupational status, and family size between the two groups. The results of Table 2 demonstrate that there was no significant difference between the mean score of awareness, attitude, subjective norms, intention, perceived behavioral control, and preventive behaviors between the two intervention and control groups before the educational program; however, after the implementation of the educational program, there was a significant increase in these variables in the intervention group, while the variables in the control group remained unchanged $(p<0.001$, Table 3).

Table 1. Comparison of quantitative variables in two groups of nursing and midwifery students of Guilan University of Medical Sciences

\begin{tabular}{l|c|c|c}
\hline \multirow{2}{*}{ Demographic variable } & \multicolumn{2}{|c|}{ Standard deviation/mean } & \multirow{2}{*}{$p$} \\
\cline { 2 - 4 } & Control group & Intervention group & $0.09^{*}$ \\
\hline Student's age & $19.30 \pm 0.96$ & $19.65 \pm 1.10$ & 0.1 \\
\hline Father's age & $49.53 \pm 4.31$ & $51.38 \pm 7.00$ & 0.8 \\
\hline Mother's age & $45.34 \pm 4.59$ & $45.59 \pm 5.92$ & 0.52 \\
\hline Family size & $4.10 \pm 0.88$ & $4.20 \pm 0.94$ &
\end{tabular}

*Independent t test

Table 2. Comparison of quantitative variables in two groups of nursing and midwifery students of Guilan University of Medical Sciences

\begin{tabular}{|c|c|c|c|}
\hline \multirow{2}{*}{ Variables } & Intervention & Control & \multirow{2}{*}{$p$} \\
\hline & $n(\%)$ & $n(\%)$ & \\
\hline \multicolumn{4}{|l|}{ Father's job } \\
\hline Self-employment & $25(48.1)$ & $23(44.3)$ & \multirow{3}{*}{0.07} \\
\hline Employee & $9(17.3)$ & $17(32.7)$ & \\
\hline Others & $18(34.6)$ & $12(23)$ & \\
\hline \multicolumn{4}{|l|}{ Mother's job } \\
\hline Housewife & $40(76.9)$ & $45(86.5)$ & \multirow{2}{*}{0.2} \\
\hline Others & $12(23.1)$ & $7(13.5)$ & \\
\hline \multicolumn{4}{|l|}{ Father's education } \\
\hline Elementary & $8(15.38)$ & $2(3.84)$ & \multirow{4}{*}{0.3} \\
\hline Guidance & $8(15.38)$ & $6(11.53)$ & \\
\hline High school and diploma & $21(40.38)$ & $25(48.07)$ & \\
\hline Academic & $15(28.86)$ & $19(36.56)$ & \\
\hline \multicolumn{4}{|l|}{ Mother's education } \\
\hline Elementary & $11(21.15)$ & $11(21.15)$ & \multirow{4}{*}{0.8} \\
\hline Middle school & $7(13.46)$ & $8(15.38)$ & \\
\hline High school and diploma & $25(48.09)$ & $26(50.01)$ & \\
\hline Academic & $9(17.30)$ & $7(13.46)$ & \\
\hline
\end{tabular}


Table 3. Mean and standard deviation of variables before and after intervention in intervention and control groups

\begin{tabular}{|c|c|c|c|c|c|}
\hline \multirow{2}{*}{ Group/time of research } & \multicolumn{2}{|c|}{ Intervention } & \multicolumn{2}{|c|}{ Control } & \multirow{2}{*}{$p$} \\
\hline & Mean & SD & Mean & SD & \\
\hline \multicolumn{6}{|l|}{ Awareness } \\
\hline Before intervention & 1.28 & 0.22 & 1.20 & 0.29 & $0.12^{*}$ \\
\hline After intervention & 1.98 & 0.05 & 1.21 & 0.28 & $<0.0001^{\star \star \star}$ \\
\hline$p$-value & \multicolumn{2}{|c|}{$<0.0001^{\star * * *}$} & \multicolumn{2}{|c|}{$0.15^{\star *}$} & - \\
\hline \multicolumn{6}{|l|}{ Attitude } \\
\hline Before intervention & 2.81 & 0.72 & 2.86 & 0.78 & $0.17^{\star \star \star}$ \\
\hline After intervention & 3.06 & 0.12 & 2.89 & 0.46 & $<0.0001^{\star *}$ \\
\hline$p$-value & \multicolumn{2}{|c|}{$<0.0001^{\star * * *}$} & \multicolumn{2}{|c|}{$0.11^{* * * *}$} & - \\
\hline \multicolumn{6}{|l|}{ Subjective norms } \\
\hline Before intervention & 2.90 & 0.57 & 2.86 & 0.56 & $0.7^{\star * *}$ \\
\hline After intervention & 3.25 & 0.73 & 2.96 & 0.32 & $0.03^{* * *}$ \\
\hline$p$-value & \multicolumn{2}{|c|}{$<0.001^{\star * * *}$} & \multicolumn{2}{|c|}{$0.19^{* * * *}$} & - \\
\hline \multicolumn{6}{|c|}{ Perceived behavioral control } \\
\hline Before intervention & 3.57 & 0.607 & 3.56 & 0.603 & $0.92^{*}$ \\
\hline After intervention & 4.77 & 0.33 & 3.63 & 0.58 & $<0.0001^{\star * *}$ \\
\hline$p$-value & \multicolumn{2}{|c|}{$<0.0001^{\star \star \star \star}$} & \multicolumn{2}{|c|}{$0.09^{* *}$} & - \\
\hline \multicolumn{6}{|l|}{ Behavioral intention } \\
\hline Before intervention & 4.02 & 0.79 & 4.01 & 0.75 & $0.8^{* * *}$ \\
\hline After intervention & 4.95 & 0.12 & 4.06 & 0.51 & $<0.0001^{\star * *}$ \\
\hline$p$-value & \multicolumn{2}{|c|}{$<0.001^{\star \star \star \star}$} & \multicolumn{2}{|c|}{$0.3^{\star \star \star \star}$} & - \\
\hline \multicolumn{6}{|l|}{ Prevention skills } \\
\hline Before intervention & 4.08 & 0.55 & 3.86 & 0.63 & $0.06^{*}$ \\
\hline After intervention & 4.97 & 0.06 & 3.96 & 0.59 & $<0.0001^{\star * *}$ \\
\hline$p$-value & \multicolumn{2}{|c|}{$<0.0001^{* * * *}$} & \multicolumn{2}{|c|}{$0.4^{\star *}$} & - \\
\hline
\end{tabular}

\section{Discussion}

This study sought to determine the effect of educational intervention based on the TPB on AIDS preventive behaviors in nursing and midwifery students of Guilan University of Medical Sciences. The findings indicated an increase in the mean score of the students' awareness of the intervention group after the intervention, while there was no significant increase in the control group. This illustrates a positive impact of the educational program provided to raise the awareness of AIDS prevention behaviors, and to engage and attract the active participation of students in the training sessions, as described by Pakpour et al., Gao et al., and Ebrahimipour et al. [18-20]. In the constructs of the TPB in the intervention group, all the constructs of the model showed a significant difference after the intervention.

With regards to the attitude in this study, it can be concluded that there was a significant increase in the intervention group after the intervention, but there was no significant increase in the control group. This finding is in line with studies by Mythili et al. [8] on the effect of educational inter- vention on AIDS in nurses and a Gao et al. [19] on the effect of educational intervention on the awareness, attitude, and preventive behaviors of the transmission of AIDS in high school students. The reason for the increase in the mean score of the attitude in the intervention group can be attributed to an increased level of awareness and information through lecture-based teaching method, using slides and educational pamphlets as well as questions and answers. Moreover, in particular group, discussion to influence attitudes, since the first step in changing behavior and the preconditions for changing attitudes is to have sufficient knowledge and awareness. In general, inadequate knowledge of adolescents and young people about AIDS and the need to refine their attitude towards this issue has been confirmed in most previous studies, which show that people's attitudes towards HIV and its spreading can have a huge impact on reducing the fear of getting infected and how to handle HIV/AIDSinfected person.

In the present study, the mean score of subjective norms in the post-interventional stage increased in the intervention 
group, which was in line with a study of Pooreh et al. [21] about the effect of education on self-care behaviors of hypertension in Iranian adolescent girls based on the TPB as well as Khani et al. study regarding educational effectiveness using TPB in screening mammography in Iranian women. However, it is inconsistent with the study by Jalambadani et al. [22] on the effect of education with the TPB on sexual function of women with breast cancer in Iran as well as the study by Jalambadani et al. [22] on the effectiveness of education based on the TPB on the sexual function of menopause women in Iran. Such inconsistency may be due to the differences in choosing the type of abstract norm. In this study, the subjective norms were peer groups. It should be noted that in various studies, other types of abstract norm have been used. Teaching by peers allows learners to better understand their values, feelings, and attitudes, and peer educators' information are easier to read, since their audience has common backgrounds, characteristics, and problems. There was a significant difference in the mean of perceived behavioral control scores after the intervention in the intervention group, which indicates a positive effect of education. This is consistent with similar studies in this regard. Perceived behavioral control suggests that if people have more control over their behavior, they are more likely to be motivated to adopt healthy behaviors. The importance of the concept of this construct is evident in preventing the occurrence of high-risk behaviors associated with AIDS.

The results of this study in the behavioral intention show that behavioral intention scores were higher in the intervention group than in the control group. This finding was similar to the results of numerous studies. The results indicated the success of educational program in increasing behavioral intention. The behavioral intention reflects the level of personal motivation for the behavior, in other words, the person's willingness to conduct the behavior. However, until appropriate training programs on preventive health behaviors are not formulated, no significant change in a behavior is possible. The findings of our study indicated that there was a significant increase in HIV prevention in the intervention group, which was consistent with the results of other studies. Furthermore, the findings showed that educational intervention using the theory of planned behavior led to an increased awareness and perceived behavioral control, improvement of attitude, and formation of appropriate abstract norms, along with the formulation of behavioral intention. Finally, the theory-based instruction increased AIDS preventive behaviors.

One of the study limitations was the use of a self-reported questionnaire. In this respect, the subjects were assured about the confidentiality of information and that the questionnaire was used without mentioning the name of the student.

\section{Conclusions}

It seems that education and intervention in the field of AIDS preventive behavior can be based on the theory of planned behavior in nursing and midwifery students, and as healthcare providers, they can be effective in promoting healthy behaviors in the community.

\section{Conflict of interest}

The authors declare no potential conflicts of interest with respect to the research, authorship, and/or publication of this article.

\section{References}

1. Jozani ZB, Mahmoodi Z, Qorbani M, Mohraz M, Dana HF. Persian translation and assessing the validity and reliability of the Questionnaire of Health Seeking Behavior of women living with HIV. HIV AIDS Rev 2019; 18: 279-284.

2. Faria NR, Rambaut A, Suchard MA, et al. The early spread and epidemic ignition of HIV-1 in human populations. Science $2014 ; 346$ : 56-61.

3. Boutayeb A. The impact of HIV/AIDS on human development in African countries. BMC Public Health 2009; 9: S3.

4. Joulaee H, Bagheri Lankarani K, Afsar Kazeroni P, Sabet M, Marzban M. Estimated number patients with HIV in fars province using capture-recapture method, 1990-2010. Hakim Research Journal 2013; 16: $128-136$.

5. Friedland G. Marking time in the global HIV/AIDS pandemic. JAMA 2016; 316: 145-146.

6. West Jr AP, Scharf L, Scheid JF, et al. Structural insights on the role of antibodies in HIV-1 vaccine and therapy. Cell 2014; 156: 633-648.

7. Karimy M, Zareban I. Predictors of HIV-preventive behavior changes among HIV-infected patients in Iran: application of the extended health belief model. Int J High Risk Behav Addict 2018 [In press].

8. Mythili D, Gandhi S, Thirumoorthy A, Vijayalakshmi P. Effect of uoncept mapping in improving nursing students' knowledge and attitudes related to care of HIV/AIDS patients. Nurs J India 2015; 106: 278.

9. Sarma H, Oliveras E. Implementing HIV/AIDS education: impact of teachers' training on HIV/AIDS education in Bangladesh. J Health Popul Nutr 2013; 31: 20.

10. SoltanianAL, Rezaei L. Assessment of oral - dental health status: using Health Belief Model (HBM) in first grade guidance school students in Hamadan. Jundishapur Journal of Health Sciences 2012; 3: 65-75 [In Persian].

11. Adefolalu AO. Cognitive-behavioural theories and adherence: application and relevance in antiretroviral therapy. Southern African Journal of HIV Medicine 2018; 19.

12. Armitage CJ, Arden MA. Exploring discontinuity patterns in the transtheoretical model: an application of the theory of planned behaviour. Br J Health Psychol 2002; 7: 89-103.

13. Ajzen I. Behavioral interventions based on the theory of planned behavior. 2006.

14. Boyle MJ, et al. Attitudes of undergraduate health science students towards patients with intellectual disability, substance abuse, and acute mental illness: a cross-sectional study. BMC Med Educ 2010; 10: 71 .

15. Farotimi AA, Nwozichi CU, Ojediran TD. Knowledge, attitude, and practice of HIV/AIDS-related stigma and discrimination reduction among nursing students in southwest Nigeria. Iran J Nurs Midwifery Res 2015; 20: 705.

16. Pickles D, King L, Belan I. Attitudes of nursing students towards caring for people with HIV/AIDS: thematic literature review. J Adv Nurs 2009; 65: 2262-2273.

17. Ajzen I. The theory of planned behaviour: reactions and reflections. Psychol Health 2011; 26: 1113-1127. 
18. Pakpour Hajiagha A, Mohammadi Zeidi I, Mohammadi Zeidi B. The impact of health education based on theory of planned behavior on the prevention of aids among adolescents. Iran J Nurs 2012; 25.

19. Gao X, Wu Y, Zhang Y, et al. Effectiveness of school-based education on HIV/AIDS knowledge, attitude, and behavior among secondary school students in Wuhan, China. PLoS One 2012; 7: e44881.

20. Ebrahimipour S, Ebrahimipoiur H, Alibakhshian F, Mohamadzadeh M. Effect of education based on the theory of planned behavior on adoption of oral health behaviors of pregnant women referred to health centers of Birjand in 2016. J Int Soc Prev Community Dent 2016; 6: 584.

21. Pooreh S, Nodeh ZH. Impact of education based on theory of planned behavior: an investigation into hypertension-preventive selfcare behaviors in Iranian girl adolescent. Iran J Public Health 2015; 44: 839.

22. Jalambadani Z, Garmaroudi G, Tavousi M. Education based on theory of planned behavior over sexual function of women with breast cancer in Iran. Asia Pac J Oncol Nurs 2018; 5: 201-207.

23. Jalambadani, Z., et al., Education based on theory of planned behavior over sexual function of menopausal women in Iran. J Midlife Health 2017; 8: 124-129.

24. Mbachu C, Dim C, Ezeoke U. Effects of peer health education on perception and practice of screening for cervical cancer among urban residential women in south-east Nigeria: a before and after study. BMC Womens Health 2017; 17: 41.

25. Bandura A. Self-efficacy. In: Corsini Encyclopedia of Psychology; 2010: p. 1-3.

26. Hohmann N, Kavookjian J. Using the Theory of Planned Behavior to determine pharmacy students' intention to participate in hormonal contraception counseling services. Curr Pharm Teach Learn 2018; 10: 1488-1495.

27. Cerqueira-Santos E, Koller S. Sexual Risk-Taking Behavior: The Role of Religiosity among Poor Brazilian Youth. Universitas Psychologica 2016. doi: http://dx.doi.org/10.11144/Javeriana.upsy15-4.srbr.

28. Huang HT, Kuo YM, Wang SR, Wang ChF, Tsai ChH. Structural factors affecting health examination behavioral intention. Int J Environ Res Public Health 2016; 13: 395. 